\title{
TLR4-RelA-miR-30a signal pathway regulates Th17 differentiation during experimental autoimmune encephalomyelitis development
}

\author{
Xuebin Qu ${ }^{1 *+}$, Jingjing Han ${ }^{2+}$, Ying Zhang ${ }^{1}$, Xingqi Wang ${ }^{3}$, Hongbin Fan ${ }^{2}$, Fang Hua ${ }^{2,4}$ and Ruiqin Yao ${ }^{1 *}$
}

\begin{abstract}
Background: Toll-like receptor 4 (TLR4) is well known for activating the innate immune system; however, it is also highly expressed in adaptive immune cells, such as CD4 ${ }^{+}$T-helper 17 (Th17) cells, which play a key role in multiple sclerosis (MS) pathology. However, the function and governing mechanism of TLR4 in Th17 remain unclear.

Methods: The changes of TLR4 in CD4 ${ }^{+} \mathrm{T}$ cells from MS patients and experimental autoimmune encephalomyelitis (EAE) mice were tested. TLR4-deficient $\left(\mathrm{TLR}^{-/-}\right)$naïve T cells were induced in vitro and transferred into Rag $1^{-/-}$ mice to measure Th17 differentiation and EAE pathology. DNA sequence analyses combining with deletion fragments and mutation analyses, chromatin immunoprecipitation (ChIP), and electrophoretic mobility shift assay (EMSA) were used to explore the mechanism of TLR4 signaling pathway in regulating Th17 differentiation.

Results: The levels of TLR4 were increased in CD4 ${ }^{+}$Th17 cells both from MS patients and EAE mice, as well as during Th17 differentiation in vitro. TLR4 ${ }^{-/} \mathrm{CD}^{+}$naïve T cells inhibited their differentiation into Th17, and transfer of $\mathrm{TLR}^{-1-} \mathrm{CD}^{+}$naïve $\mathrm{T}$ cells into Rag ${ }^{-1-}$ mice was defective in promoting EAE, characterized by less demyelination and Th17 infiltration in the spinal cord. TLR4 signal enhanced Th17 differentiation by activating RelA, downregulating the expression of miR-30a, a negative regulator of Th17 differentiation. Inhibition of RelA activity increased miR-30a level, but decreased Th17 differentiation rate. Furthermore, RelA directly regulated the expression of miR-30a via specific binding to a conserved element of miR-30a gene.
\end{abstract}

Conclusions: $\mathrm{TLR}^{-/-} \mathrm{CD}^{+}$naïve $T$ cells are inadequate in differentiating to Th17 cells both in vitro and in vivo. TLR4RelA-miR-30a signal pathway regulates Th17 differentiation via direct binding of RelA to the regulatory element of miR30a gene. Our results indicate modulating TLR4-RelA-miR-30a signal in Th17 may be a therapeutic target for Th17mediated neurodegeneration in neuroinflammatory diseases.

Keywords: Multiple sclerosis, T helper cell, Differentiation, Neuroinflammation, TLR4, RelA, MiR-30a

\section{Background}

Multiple sclerosis (MS) is an inflammatory demyelinating syndrome of the central nervous system (CNS) that is characterized by progressive immune-mediated destruction of the myelin sheath and accumulated neurological disability $[1,2]$. Main contributors to

\footnotetext{
*Correspondence: 100002012036@xzhmu.edu.cn; wenxi_yao@163.com ${ }^{+}$Xuebin Qu and Jingjing Han contributed equally to this work.

'Department of Cell Biology and Neurobiology, Xuzhou Key Laboratory of Neurobiology, Xuzhou Medical University, Xuzhou 221009, Jiangsu, People's Republic of China

Full list of author information is available at the end of the article
}

myelin sheath damage are activated myelin-reactive $\mathrm{T}$ cells that infiltrate the CNS, triggering an immunologic cascade [3, 4]. In MS and an experimental autoimmune encephalomyelitis (EAE) mouse model, mature and excessively activated IL-17-secreting $\mathrm{T}$ helper cells 17 (Th17) are major initiators and participants involved in promoting pathology. Infusion of Th17 cells or injection of IL-17 can effectively aggravate disease, while IL-17deficient mice have alleviated pathology [5]. In addition, it has been shown that the pathogenicity of autoreactive Th17 in mice is linked with their production of GM-CSF

(c) The Author(s). 2019 Open Access This article is distributed under the terms of the Creative Commons Attribution 4.0 International License (http://creativecommons.org/licenses/by/4.0/), which permits unrestricted use, distribution, and 
[6-8]. Thus, downregulation of the immune response, especially Th17 cell differentiation and activation, may be an effective treatment strategy for MS.

Toll-like receptors (TLRs) are important innate immune proteins that play critical roles in initiating inflammatory responses and promoting adaptive immune responses responsible for the identification and clearance of invading pathogens [9]. Inappropriate activation of TLRs, such as TLR4, and downstream pathways have been implicated in certain autoimmune diseases, including MS [10]. TLR4 is upregulated in patients with MS and in the spinal cord of EAE mice $[1,11-13]$. In vivo, treatment with TLR4 ligands, such as LPS, aggravates EAE, while targeted disruption of TLR4 prevents EAE [14-19]. Activation of TLR4 produces high levels of proinflammatory cytokines including IL-1 $\beta$ and IL-6 $[20,21]$, which initiate differentiation of Th17 cells. Activated Th17 cells can secrete IL-17 and GM-CSF $[6,7,22,23]$, resulting in a CNS autoimmunity for demyelination. Besides innate immune cells such as microglia and macrophages, TLR4 is also expressed in a wide range of adaptive immune cells including $\mathrm{CD} 4^{+} \mathrm{T}$ cells, even higher in Th17 cells than in Th1 and Th2 cells $[24,25]$. However, little is known about the role of TLR4 activation in Th17.

It has been shown that $\mathrm{TLR} 4^{-/-} \mathrm{CD} 4^{+} \mathrm{T}$ cells almost completely abrogate EAE symptoms through blunted Th17 activation and defective IL-17 production [25]. Consistently, $\mathrm{CD}^{+}$naïve $\mathrm{T}$ cells stimulated through the TLR4 pathway proliferate more extensively and exhibit enhanced survival in vitro [25]. Although TLR4 activation plays a role in Th17 proliferation, several questions remain unanswered, including (1) the inconsistent role of TLR4 activation on Th17 differentiation in vitro and in vivo and (2) the molecular mechanisms that govern Th17 differentiation following TLR4 stimulation in CD4 ${ }^{+} \mathrm{T}$ cells.

MicroRNAs (miRNAs) have been established as powerful regulators of gene expression in normal physiological, as well as in pathological, conditions. Also, miRNAs can serve as diagnostic biomarkers and therapeutic targets for many diseases [26, 27]. Many researchers have identified major factors participating in miRNA biogenesis and established basic principles of miRNAs function [28], but the upstream transcriptional regulation of these miRNAs is not well understood. Limited studies show that miRNA expression can be directly regulated by epigenetic alterations, such as DNA methylation [29-31] and histone modification [32, 33]. In addition, transcription factors, such as NF- $\kappa B$, MYC, REST, and STAT, are thought to regulate miRNA transcription in a similar manner to that of protein-coding genes by binding to conventional DNA binding sequences located in or near regulatory regions that lie upstream of microRNA genes [28, 34-37]. Based on our earlier data, the disordered miR-30a level in vivo contributes to Th17 ratio imbalance and EAE pathology [38]; however, the reasons for dysregulated expression of miR-30a in EAE mice and MS patients are unclear. Interestingly, by bioinformatic analyses, we find several potential binding sites of RelA, a nuclear transcription factor that is activated by TLR4, in the promoter region of miR30a gene, suggesting a possible regulating role of TLR4RelA on miR-30a expression.

In this paper, our results demonstrate that $\mathrm{TLR}^{-/-}$ $\mathrm{CD}^{+}$naïve $\mathrm{T}$ cells are inadequate in differentiating to Th17 cells both in vitro and in vivo. Furthermore, TLR4-RelA-miR-30a signal pathway regulates Th17 differentiation via direct binding of RelA to the regulatory element of miR-30a gene.

\section{Materials and methods}

Clinical subjects

MS patients (Additional file 1: Table S1) were recruited in Affiliated Hospital of Xuzhou Medical University and Xuzhou Central Hospital. All participants were examined by neurologists for expanded disability status scale measures [39]. Peripheral blood samples were obtained from MS patients as well as age- and sex-matched healthy volunteers. Written informed consents were obtained from all of the participants. Research protocols were approved by the appropriate institution review boards.

\section{Mice and EAE induction}

C57BL/6 wild-type (WT) mice were purchased from SLAC Laboratory Animal Co., Ltd. (Shanghai, China). TLR4 ${ }^{-/-}$ and Rag1 ${ }^{-1-}$ mice were from the Model Animal Research Center of Nanjing University (Nanjing, China). All mice were housed under specific pathogen-free conditions in the Xuzhou Medical University animal facility (Xuzhou, China). All experiments were performed in accordance with the Provisions and General Recommendations of the Chinese Experimental Animal Administration Legislation, as well as institutional approval from the Xuzhou Medical University Experimental Animal Ethics Committee.

The EAE model was performed as described previously [38]. Briefly, female mice 7-8 weeks old were immunized subcutaneously with $100 \mu \mathrm{g}$ MOG 35-55 (MEVGWYRSPFSRVVHLYRNGK) (GL Biochem, Shanghai, China) in complete Freund's adjuvant (Sigma-Aldrich, St. Louis, MO, USA) containing $4 \mathrm{mg} / \mathrm{mL}$ heat-killed Mycobacterium tuberculosis H37Ra (BD Bioscience, San Jose, CA, USA). Each mouse was administered intraperitoneally (i.p.) with $200 \mathrm{ng}$ pertussis toxin (Sigma-Aldrich, USA) twice, on the day of immunization and $48 \mathrm{~h}$ later. All of the mice were weighted daily, and the ratio of body weight was normalized to the initial weight of each mouse. Clinical assessment of EAE was performed daily according to the following criteria: 0 , no clinical signs; 1 , 
paralyzed tail; 2, paresis (weakness, incomplete paralysis of one or two hindlimbs); 3, paraplegia (complete paralysis of both hindlimbs); 4, paraplegia with forelimb weakness or paralysis; and 5, moribund state or death.

\section{$\mathrm{CD}^{+}$naïve $\mathrm{T}$ cell culture, purification, transfer, and induction}

$\mathrm{CD}^{+}$naïve $\mathrm{T}$ cells from splenocytes of 5 - to 6 -week-old mice were purified by magnetic cell sorting according to the manufacturer's instructions (Miltenyi Biotec, Bergisch Gladbach, Germany). Briefly, non-naïve $\mathrm{CD}^{+} \mathrm{T}$ cells were indirectly magnetically labeled by using a cocktail of biotin-conjugated antibodies and anti-biotin microbeads. Memory T cells were directly magnetically labeled with CD44 microbeads. Isolation of pure naïve T cells was achieved by depletion of magnetically labeled non-target cells. For adoptive transfer studies, each recipient Rag1 $1^{-/-}$mouse was injected intravenously in tail veins with $5 \times 10^{6} \mathrm{CD}^{+}$naïve $\mathrm{T}$ cells on the day before EAE immunization.

For Th17 differentiation, the purified $\mathrm{CD}^{+}$naïve $\mathrm{T}$ cells were cultured for 3 days under Th17 cell-polarizing conditions (RPMI-1640 containing 10\% FBS, $1 \mathrm{mM}$ glutamine, $0.1 \mathrm{mM}$ b-mercaptoethanol, $1 \%$ nonessential amino acids (Sigma-Aldrich, USA), anti-CD3 plus antiCD28-coated beads (Invitrogen, CA, USA), $5 \mathrm{ng} / \mathrm{mL}$ IL-2 (R\&D Systems Inc., Minneapolis, MN, USA), $20 \mathrm{ng} / \mathrm{mL}$ IL-6, $5 \mathrm{ng} / \mathrm{mL}$ transforming growth factor- $\beta, 10 \mathrm{ng} / \mathrm{mL}$ IL-23, $2 \mu \mathrm{g} / \mathrm{mL}$ anti-IL-4, and $2 \mu \mathrm{g} / \mathrm{mL}$ anti-interferon- $\gamma$ (BD Bioscience, USA). In some experiments, $10 \mu \mathrm{g} / \mathrm{ml}$ LPS (Sigma-Aldrich, USA), $5 \mu \mathrm{M}$ TPCA-1 (Abcam, Cambridge, UK), or $10 \mu \mathrm{M}$ Helenalin (Abcam, UK) were used.

To enrich IL-17 ${ }^{+}$Th17 [38], cells were incubated with Cell Stimulation Cocktail (eBioscience, CA, USA) for $5 \mathrm{~h}$, and then purified by magnetic cell sorting according to manufacturer's instructions (Miltenyi Biotec, Germany): briefly, an IL-17-specific catch reagent was attached to the cell surface to bind with the secreted IL-17 from positive, secreting cells. These cells were subsequently labeled with a second IL-17-specific antibody conjugated to biotin, and then incubated with anti-biotin antibody conjugated to Rphycoerythrin (PE). Then, the IL-17-secreting cells were magnetically labeled with anti-PE microbeads and enriched in the magnetic field.

\section{Histological analyses}

After anesthesia with pentobarbital, mice were perfused with normal saline and then buffered $4 \%$ paraformaldehyde. Following standard protocols, paraffin-embedded sections of spinal cords were stained with hematoxylin and eosin (H\&E) or luxol fast blue (LFB) for analysis of inflammation or demyelination, respectively. For H\&E staining, sections were deparaffinized, rehydrated, and stained in hematoxylin solution for $8 \mathrm{~min}$. Then, the sections were rinsed in distilled water and 95\% ethyl alcohol, followed by counterstain in eosin solution for 1 min. After dehydrated through ethyl alcohol and cleared in xylene, the stained sections were mounted for observation. Spinal cord infiltrates were quantified as infiltrates per square millimeter in five non-serial H\&Estained sections from each mouse in a blinded manner. For LFB staining, the deparaffinized sections were hydrated in $95 \%$ ethyl alcohol, then stained in luxol fast blue solution at $56^{\circ} \mathrm{C}$ overnight. After rinse in $95 \%$ ethyl alcohol and distilled water, sections were differentiated with lithium carbonate solution and 70\% ethyl alcohol. Then, the sections were rinsed, dehydrated, cleared, and mounted for observation. Demyelination was quantified by calculation of regional mean optical density (MOD) relative to the total value in five non-serial LFB-stained sections from each mouse in a blinded manner.

For immunofluorescence staining, prepared spinal cords were incubated overnight in sodium phosphate buffer containing 30\% sucrose, then embedded in Optimal Cutting Temperature medium (Leica, Solms, Germany) for sectioning. Cryosections $(15 \mu \mathrm{m})$ were thawed, washed with $5 \%$ normal goat serum and $0.3 \%$ Triton X-100 in $0.01 \% \mathrm{PBS}$, and then incubated with primary monoclonal antibody (CST, MA, USA) overnight at $4{ }^{\circ} \mathrm{C}$. Following an additional wash step, specimens were incubated with goat anti-mouse or goat anti-rabbit fluorescently conjugated secondary antibodies (Santa Cruz, CA, USA), and cell nucleus was counterstained with 4',6-diamidino-2-phenylindole (Vicmed, Xuzhou, China). Images were acquired using a fluorescence microscope system (Olympus, Tokyo, Japan), and MFI values were calculated using ImageJ software.

\section{Quantitative RT-PCR}

Cells were lysed by TRIzol (Invitrogen, USA) for RNA isolation. One microgram of total RNA from each sample was reverse-transcribed using a QuantScript RT kit (Tiangen, Beijing, China) and examined with a SYBR Green real-time PCR kit (Roche, Basel, Switzerland). To test the miR-30a expression, $500 \mathrm{ng}$ total RNA from each sample was performed using a MiRcute MiRNA Kit (Tiangen, China). Relative expression of mRNA or miRNA was evaluated by the $2^{-\Delta \Delta C t}$ method in LightCycler ${ }^{\circ} 480$ System (Roche, Switzerland) and normalized to the expression of $\beta$-actin or $\mathrm{U} 6$ respectively. The primers were listed in Additional file 2: Table S2.

\section{Western blotting}

Tissues or cells were stripped and ultrasonically homogenized in RIPA buffer, then quantified by a bicinchoninic acid protein assay kit (Beyotime, Shanghai, China). Protein samples were separated by electrophoresis in an 
SDS denaturing $10 \%$ polyacrylamide gels and transferred to nitrocellulose membranes. Membranes were blocked in $0.01 \%$ PBS containing 5\% BSA, incubated overnight at $4{ }^{\circ} \mathrm{C}$ with primary antibodies, and then incubated in IRDye-conjugated secondary antibodies (LI-COR, CA, USA). Membranes were scanned using an Odyssey Infrared Imaging System Scanner (LI-COR, USA), and images were analyzed using ImageJ software.

\section{ELISA}

Quantikine ELISA kits to measure IL-17A, IL-17F, and GM-CSF concentration were obtained from Westang Biological Technology Co., Ltd. (Shanghai, China) and used according to the manufacturer's instructions. All samples were measured in duplicate.

\section{Flow cytometric analyses}

Whole blood from clinical participant was collected by venipuncture in heparinized tubes and layered over Human Lymphocyte Separation Medium (Dakewe, Shenzhen, China) to obtain peripheral blood lymphocytes. Then, fluorescent-labeled antibodies, such as anti-CD4, CD45RA, or CD45RO (Miltenyi Biotec, Germany) were added and incubated for $30 \mathrm{~min}$ at $4{ }^{\circ} \mathrm{C}$. For $\mathrm{CD} 4^{+} \mathrm{IL}-17^{+} \mathrm{T}$ cell isolation, the peripheral blood lymphocytes were incubated with Cell Stimulation Cocktail (eBioscience, USA) for $5 \mathrm{~h}$ before $\mathrm{CD} 4$ staining, and then resuspended in fixation/ permeabilization solution (BD Pharmingen, USA), after which anti-IL-17 fluorescent-labeled antibody (Miltenyi Biotec, Germany) was added and incubated for $30 \mathrm{~min}$ at room temperature. Finally, the labeled cells were acquired by flow cytometer (BD Biosciences, USA).

Peripheral blood, splenocytes, lymph nodes, and type I collagenase digested spinal cords from mice were collected; then, lymphocytes were prepared by Percoll gradient centrifugation. To detect intracellular cytokine levels, cells were incubated with Cell Stimulation Cocktail (eBioscience, USA) for $5 \mathrm{~h}$, then cells were resuspended in fixation/ permeabilization solution (BD Pharmingen, USA) and stained with anti-IL-17 and GM-CSF antibodies (Miltenyi Biotec, Germany) according to the manufacturer's protocol. In some experiments, staining with anti-RelA antibody (CST, USA) and APC-conjugated secondary antibody (Miltenyi Biotec, Germany) was performed. Tests were performed on MACSQuantTM Flow Cytometers (Miltenyi Biotec, Germany) and analyzed with FlowJo software. Protein expression level was expressed as mean fluorescence intensity (MFI).

\section{DNA sequence analyses}

Mmu-miR-30a precursor (MI0000144) DNA sequence (chr1:23272269-23272339), $5 \mathrm{~kb}$ spanning sequence upstream, and $1 \mathrm{~kb}$ spanning sequence downstream of transcription start site were obtained from miRBase (http://www.mirbase.org/) [40] and UCSC (http://gen ome.ucsc.edu/ENCODE/) [41]. Highly conservative transcription factor binding site clusters across three closely related mammals: mouse, human, and chimp, were aligned by ECR Browser (https://ecrbrowser.dcode.org/) [42] according to website instructions. Transcription factor binding sites were predicted using the JASPAR openaccess database (jaspar.genereg.net/) [43] and rVista 2.0 online database (https://rvista.dcode.org/) [44] following website instructions.

\section{Plasmid construction and dual-luciferase reporter assay}

Five regulatory element deletion fragments were amplified using primers (Additional file 3: Table S3). The purified PCR products were digested with $K p n \mathrm{I}$ and $\mathrm{XhoI}$ and ligated into the pGL4.20[luc2Puro] vector (Promega, WI, USA). For the binding site mutation assay, synthesized DNA sequences containing mutated binding sites were cloned into the pGL4.20[luc2Puro] vector.

Recombinant plasmids and internal control vector PRL-TK Renilla vector were transfected into Jurkat cells using Lipofectamine 2000 reagent (Invitrogen, USA) following the instructions. Cells were harvested at $48 \mathrm{~h}$ post-transfection and assayed for luciferase activity using the Dual-Luciferase Reporter Assay System (Promega, USA).

\section{Electrophoretic mobility shift assays}

Cellular nuclear protein was extracted with Nucleoprotein Extraction Kit (Beyotime, China). Double-stranded oligonucleotides (Sangon, Shanghai, China) corresponding to the RelA binding sites of the mmu-miR-30a precursor regulatory elements were synthesized and annealed into double strands. The probes are listed in Additional file 4: Table S4.

A total of $12 \mu \mathrm{g}$ nuclear extract was added to $0.1 \mu \mathrm{M}$ biotin-labeled double-stranded oligonucleotides in $1 \times$ EMSA/Gel-Shift binding buffer, while extra $5 \mu \mathrm{M}$ unlabeled competitor oligonucleotide was added in the control group and $2 \mu \mathrm{g}$ of RelA antibody was needed for the super-shift reaction. Mixtures were incubated at $24^{\circ} \mathrm{C}$ for $20 \mathrm{~min}$, analyzed by electrophoresis in $4 \%$ polyacrylamide gels at $10 \mathrm{~V} / \mathrm{cm}$, and then transferred to a nylon membrane. Membranes were UV-light cross-link, incubated with HRP-conjugated Streptavidin, and developed with chemiluminescences.

\section{Chromatin immunoprecipitation assay}

ChIP assays were performed using an $\mathrm{EZ}^{-\mathrm{ChIP}^{\mathrm{m}}}$ kit (Millipore, MA, USA) according to the manufacturer's instructions. Briefly, chromatin was crosslinked with $1 \%$ formaldehyde at $37^{\circ} \mathrm{C}$ for $10 \mathrm{~min}$ and reactions were neutralized with glycine for $5 \mathrm{~min}$ at room temperature. Cells were then harvested, lysed, and sonicated. Nuclear 
lysates were sonicated 15 times for $4.5 \mathrm{~s}$ each with $9 \mathrm{~s}$ intervals on ice water using a Scientz-IID (Scientz, Zhejiang, China). After incubation with Protein A Agarose/Salmon Sperm DNA at $37^{\circ} \mathrm{C}$ for $1 \mathrm{~h}$, an equal amount of chromatin was immuno-precipitated at $4{ }^{\circ} \mathrm{C}$ overnight with at least $1 \mu \mathrm{g}$ of RelA (Abcam, UK) or isotype IgG antibodies. Immuno-precipitated products were collected after incubation with Protein A Agarose/Salmon Sperm DNA, and then, the bound chromatin was eluted in ChIP elution buffer. The proteins were digested with Proteinase $\mathrm{K}$ for $2 \mathrm{~h}$ at $45^{\circ} \mathrm{C}$, and the DNA was purified for PCR test. Primers for PCR were listed in Additional file 5: Figure S1.

\section{Statistical analyses}

The results were expressed as mean \pm standard deviation (SD) and analyzed by SPSS 17.0. Independent sample $t$ tests were used to evaluate the differences between groups. One-way analysis of variance (ANOVA) followed by Bonferroni's post hoc test was used for multiple comparisons. Body weights and clinical scores were evaluated by two-way repeated measures ANOVA. A $P$ value of 0.05 or less was considered significant.

\section{Results}

TLR4 is increased in Th17 during EAE and MS

\section{development}

We collected peripheral blood $\mathrm{CD}^{+} \mathrm{T}$ cells from MS patients and healthy controls and found MS patients had a more significantly upregulated expression of TLR4
(> 5 folds) in $\mathrm{CD} 45 \mathrm{RO}^{+}$memory $\mathrm{CD}^{+} \mathrm{T}$ cells than $\mathrm{CD}_{45 \mathrm{RA}^{+}}$naïve $\mathrm{T}$ cells compared with that in healthy controls ( $<2$ folds) (Fig. 1a). As Th17 cells are key participants involved in MS development, we enriched IL-17 ${ }^{+}$Th17 cells and found Th17 cells from MS patients expressed more IL-17 and TLR4 than those from healthy controls (Fig. 1a'). Similarly, in EAE mice, TLR4 was also increased dramatically in Th17 cells from peripheral blood, spleen, and draining lymph nodes (Fig. 1b). Moreover, as EAE was more aggravated (i.e., score increased), the level of TLR4 was correspondingly increased (Fig. 1c). To further explore the relationship between TLR4 expression and Th17 cells, we induced $\mathrm{CD} 4^{+}$naïve $\mathrm{T}$ cells into Th17 in vitro and found that TLR4 had a gradually ascending pattern with reaching its peak at $48 \mathrm{~h}$, then kept a high expression until $72 \mathrm{~h}$ (Fig. 1d). These phenomena suggest that TLR4 in $\mathrm{CD} 4^{+} \mathrm{T}$ cells may play a role in Th17 differentiation and MS development.

\section{TLR4 deficiency inhibits the generation of Th17 cell in vitro}

To determine the role of TLR4 in Th17 differentiation, $\mathrm{CD}^{+}$naïve $\mathrm{T}$ cells from $\mathrm{TLR}^{-/-}$mice (Fig. 2a) were cultured under Th17-polarizing conditions with or without LPS. Data showed that TLR4 deficiency led to a lower percentage of induced $\mathrm{IL}-17^{+}$cells, even LPS, which is an activator of Th17 differentiation, could not increase the $\mathrm{IL}-17^{+}$cells in the

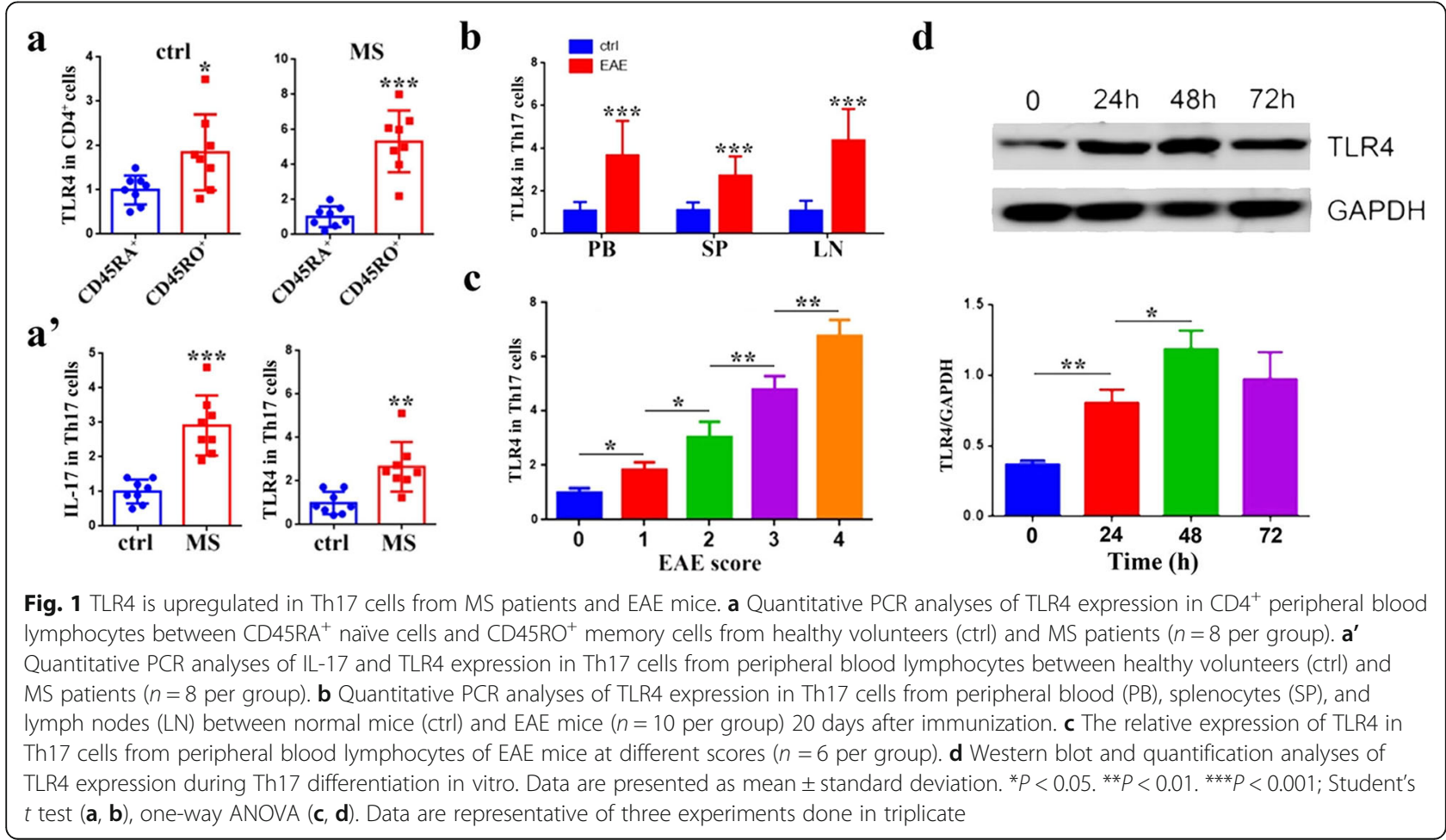




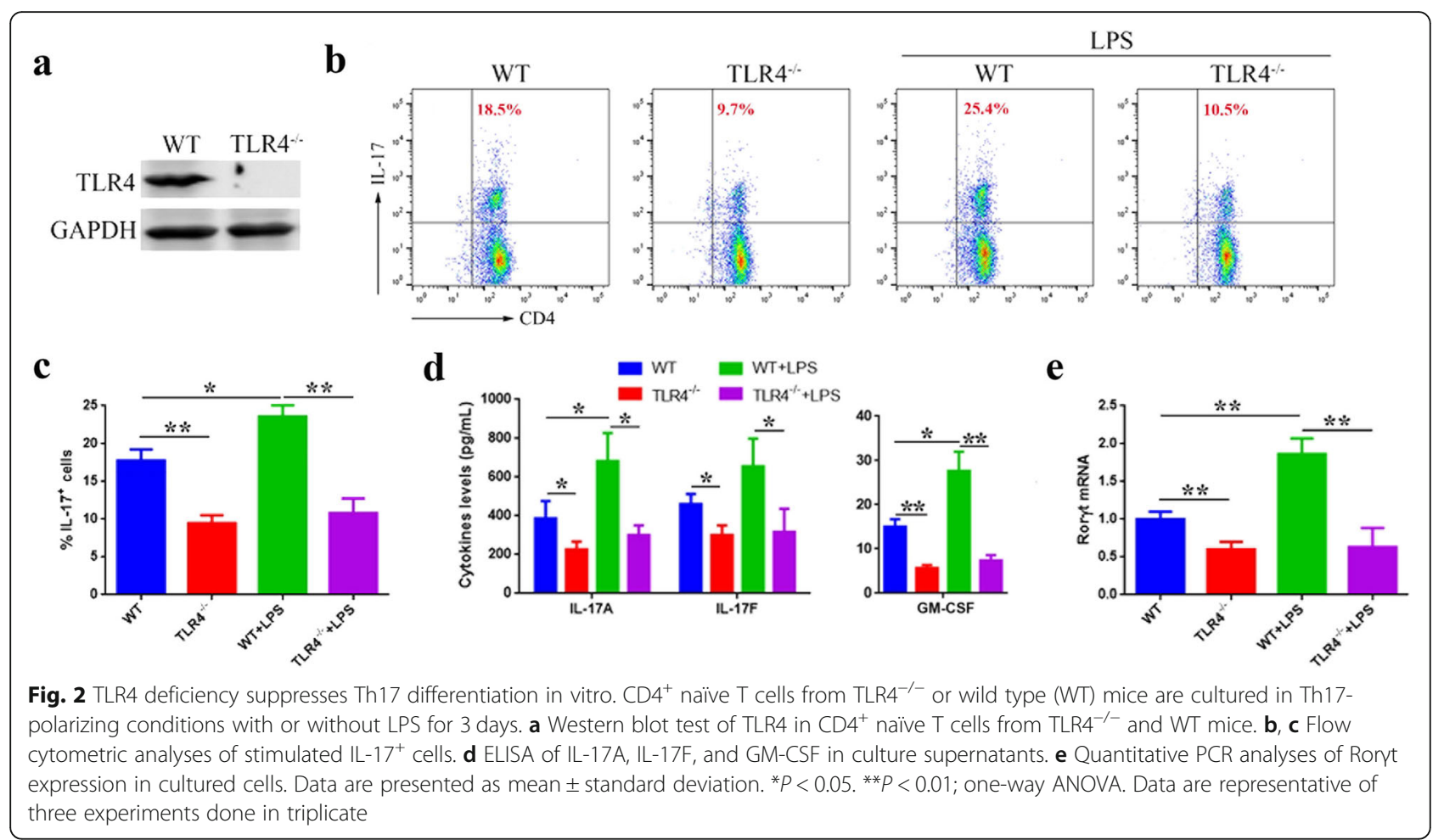

absence of TLR4 (Fig. 2b, c). Secretion of the Th17related cytokines, IL-17A, IL-17F, and GM-CSF (Fig. 2d), as well as expression of the lineage marker gene, Roryt (Fig. 2e), was significantly downregulated in $\mathrm{TLR}_{4}^{-1-} \mathrm{T}$ cells, even in the presence of LPS. These results indicate that TLR4 contributes to Th17 differentiation.

$\mathrm{TLR}^{-/-} \mathrm{CD}^{+}$naïve $\mathrm{T}$ cells are defective in promoting EAE To further clarify the role of TLR4 in the generation of Th17 cells in vivo, we transferred TLR4 ${ }^{-1-} \mathrm{CD} 4^{+}$naïve $\mathrm{T}$ cells into age-matched $\operatorname{Rag} 1^{-1-}$ mice, which were then induced for EAE. In sharp contrast with control, mice receiving TLR4 ${ }^{-1-} \mathrm{CD} 4^{+}$naïve $\mathrm{T}$ cells had a less weight loss (Additional file 6: Figure S2), exhibited a lower EAE incidence, and developed a delayed onset with reduced EAE severity (Table 1, Fig. 3a). Histological analyses of spinal cord sections showed that TLR4 $4^{-\gamma} \mathrm{CD} 4^{+}$naïve $\mathrm{T}$ cell-transferred mice had minimal inflammatory infiltration (Fig. 3b) and demyelination (Fig. 3b'), which was further supported by the result of increased MOG (Figs. 3b", c), a protein involved in structural integrity to the myelin sheath. Compared with the WT group, the proportions of $\mathrm{IL}-17^{+}$cells in the peripheral blood and spinal cord-infiltrated lymphocytes were much lower in $\mathrm{TLR}^{-1-} \mathrm{CD}^{+}$naïve $\mathrm{T}$ cell-transferred mice (Fig. 3d). Similarly, the concentration of IL-17A, IL-17F, and GMCSF in the serum (Fig. 3e) and the expression of Roryt in the lymphocytes from peripheral blood (Fig. 3f) were significantly decreased. Furthermore, draining lymph node cells and splenocytes from these mice were restimulated in vitro, and data showed that among the $\mathrm{CD}^{+}{ }^{+} \mathrm{T}$ cells, $\mathrm{IL}_{-17} 7^{+}$and $\mathrm{GM}-\mathrm{CSF}^{+}$cells were both decreased dramatically when TLR4 was deficient (Fig. 3g). Correspondingly, TLR4 ${ }^{-1-}$ lymphocytes secreted less IL17A, IL-17F, and GM-CSF (Fig. 3h). The data presented above collectively demonstrate that TLR4 deficiency in $\mathrm{CD}^{+}$naïve $\mathrm{T}$ cells can inhibit Th17 differentiation in vivo, resulting in mild EAE.

\section{TLR4 regulates miR-30a expression via RelA}

Our previous data showed that the differentiation of Th17 could be negatively regulated by miR-30a, whose expression was decreased gradually during Th17

Table 1 EAE disease parameters

\begin{tabular}{lllll}
\hline Group & Incidence & Day of onset & Peak score & $\begin{array}{l}\text { Cumulative score } \\
\text { (until day 20) }\end{array}$ \\
\hline WT & $93.3 \%(14 / 15)$ & $6.0 \pm 0.7$ & $3.4 \pm 0.5$ & $26.6 \pm 3.4$ \\
TLR4 $^{-/-}$ & $60.0 \%(9 / 15)$ & $10.4 \pm 2.0^{* *}$ & $1.0 \pm 0.4^{* * *}$ & $13.2 \pm 4.6^{* * *}$ \\
\hline
\end{tabular}

Data are presented as mean \pm standard deviation. ${ }^{* *} P<0.01$. ${ }^{* * *} P<0.001$; Student's $t$ test 


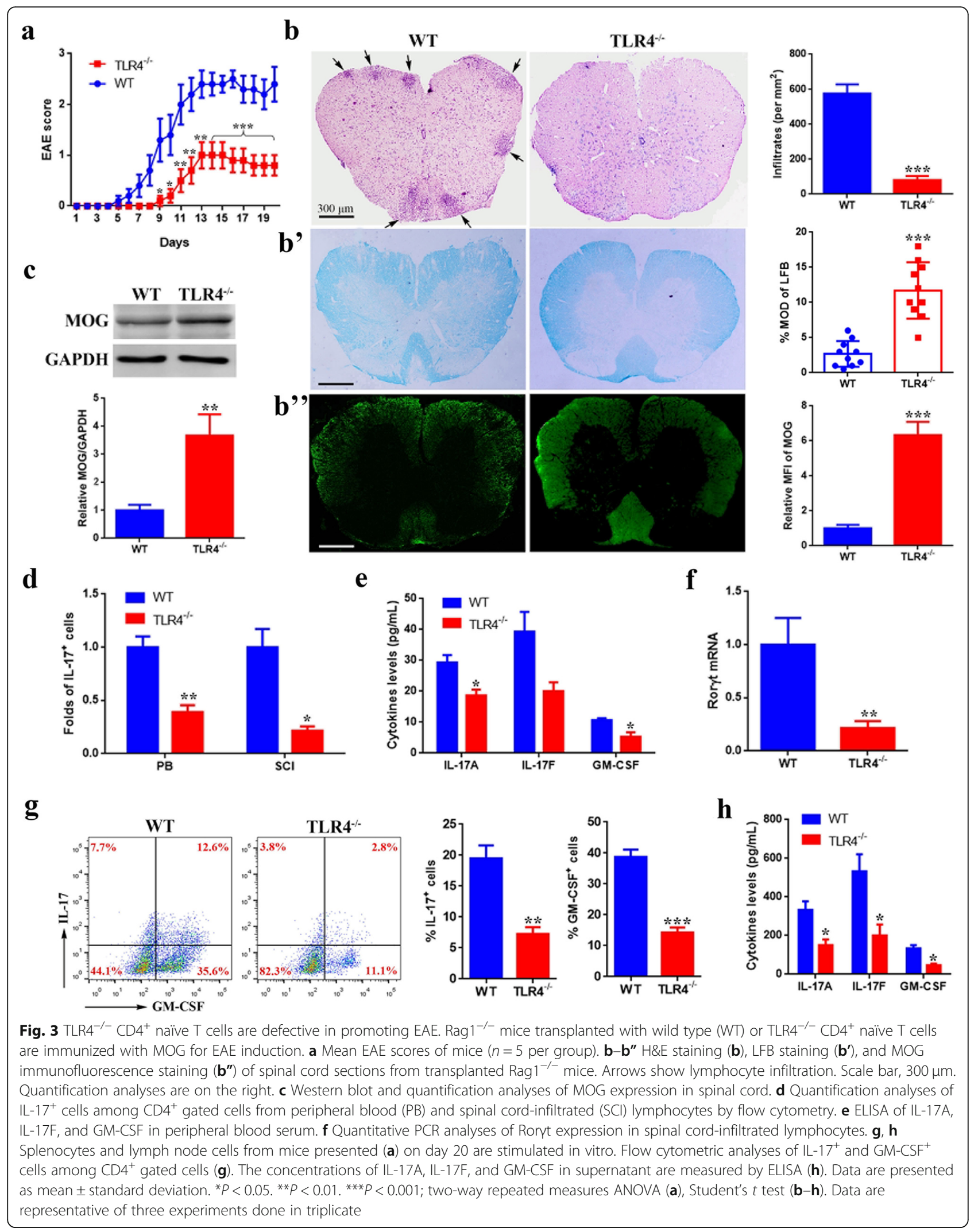


generation [38]. Interestingly, the miR-30a level had a negative correlation with the expression of TLR4 in the process of Th17 differentiation (Fig. 4a), even showed a significant increase in $\mathrm{TLR}^{-/-}$Th17 cells (Fig. 4b), suggesting a regulating role of TLR4 on miR-30a expression. Furthermore, we found RelA, a nuclear transcription factor that is activated by TLR4, was upregulated in correlation with increased EAE disease score, while the level of miR-30a was decreased accordingly (Fig. 4c). Similarly, compared with healthy controls, MS patients had increased RelA but decreased miR-30a (Fig. 4d).

To clarify whether TLR4 could regulate miR-30a expression via RelA, we used the LPS, a TLR4 agonist; TPCA1, an IKK-2 inhibitor [45]; and helenalin, a RelA inhibitor [46] during Th17 differentiation in vitro. The results showed that LPS treatment could downregulate the expression of miR-30a (Fig. 4e), resulting in a larger percentage of induced IL- $17^{+}$cells (Fig. 4f, g) with increased IL-17, GM-CSF secretion (Fig. 4h), and Roryt expression (Fig. 4i), while inhibitor-treated $\mathrm{CD}^{+}$naïve $\mathrm{T}$ cells had a raised miR-30a level (Fig. 4e), lower IL-17 cell percentage (Fig. 4f, g), and decreased IL-17, GMCSF secretion (Fig. 4h), and Roryt expression (Fig. 4i). These data show a negative regulatory role of RelA on miR-30a expression during Th17 differentiation.

\section{RelA recognizes specific sites in the regulatory elements of miR-30a gene}

To explore the regulatory mechanism of RelA on miR30a expression, we scanned the DNA sequence $5000 \mathrm{bp}$ upstream and $1000 \mathrm{bp}$ downstream of the miR-30a gene and discovered several predicted transcription factors binding site clusters (I-VII) with a high nucleotide conservation across three closely related mammals of

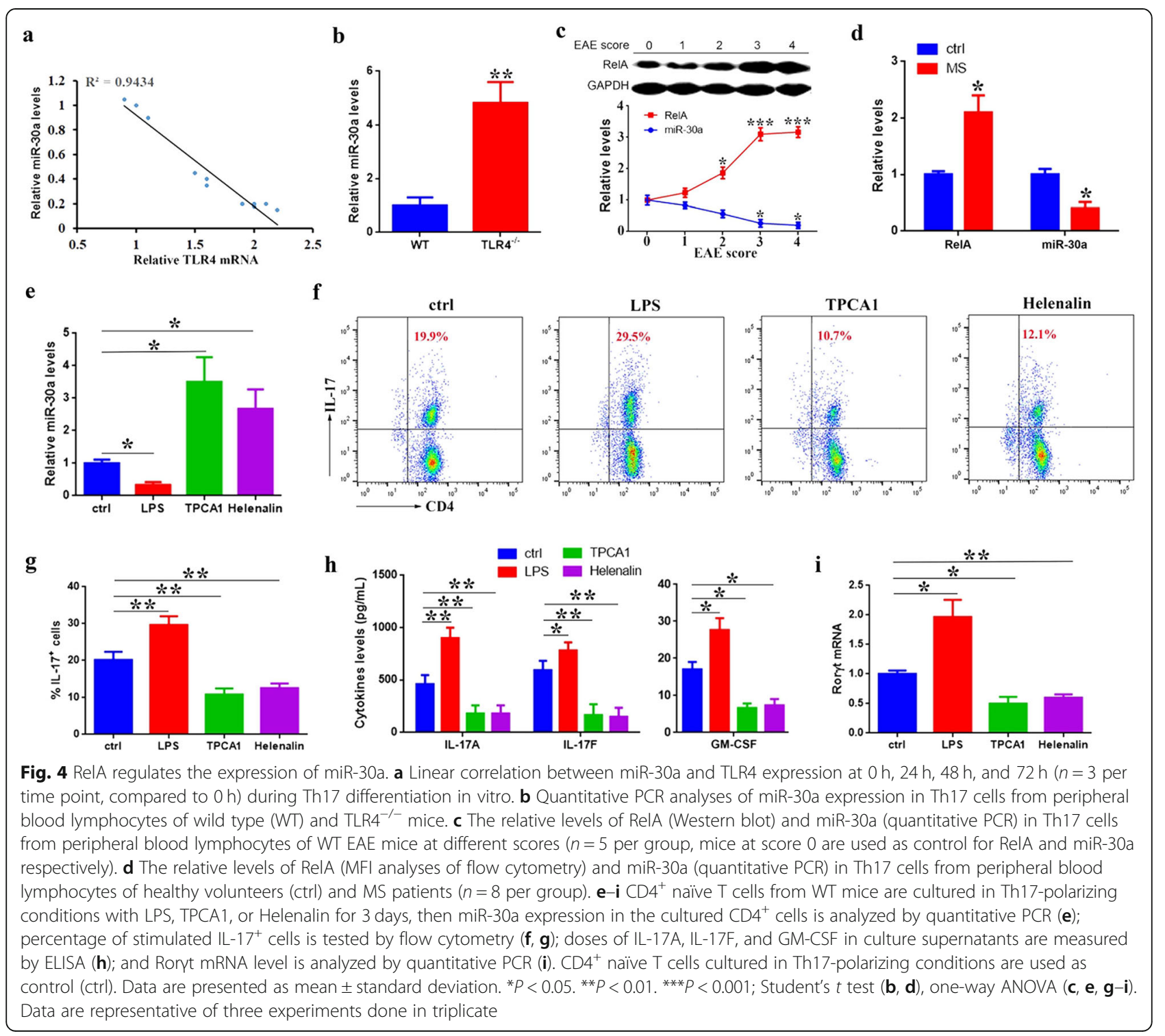


mouse, human, and chimp (Fig. 5a). Next, different deleted DNA sequences carrying different clusters (Fig. 5b, left) were constructed for luciferase analyses, and the results revealed that deletion of cluster I and cluster II resulted in a much higher transcriptional activity than that in the construct carrying all clusters (Fig. 5b), suggesting the presence of a negative regulatory region located within cluster I and cluster II.

To explore the special transcription factors binding with cluster I and cluster II to regulate miR-30a transcription, we analyzed the promoter sequence in JASPAR and rVista 2.0 database and found several RelA binding motifs were located within the predicted transcription factor binding site clusters, especially concentrated in cluster II (Fig. 5c, Additional file 7: Figure S3). Next, we performed ChIP and EMSA experiments to determine whether RelA was able to bind directly to the putative binding sites, BS-1, BS-2, and BS-3, in cluster II (Additional file 5: Figure S1). ChIP results showed that the BS-1 and BS-2 fragments were significantly enriched after RelA immunoprecipitation, whereas no signal was observed at BS-3 (Fig. 5d, Additional file 8: Figure S4). Furthermore, in EMSA experiments, we observed that RelA bound to the BS-1 probe and this interaction disappeared by competition with an unlabeled probe (Fig. 5e). However, no specific supershift band was observed with the use of BS-2 probe (Additional file 9: Figure S5), suggesting BS-2 is not a true binding site of RelA.

To further determine the binding site of RelA in cluster II, site-mutated BS-1 and BS-2 were constructed (Fig. 5f, left). Mutations in BS-1 increased luciferase activity, while no difference was observed in constructs containing mutated BS-2 (Fig. 5f). Taken together, the above data demonstrate that RelA can modulate the expression of miR-30a via direct binding to BS-1 in cluster II.

\section{Discussion}

Excessive differentiation and activation of Th17 is a key player in inducing inflammation in many autoimmune diseases [47-49]. However, it is still not clear how to mitigate Th17 immune response during MS and EAE to reduce pathology. Here, we explore the direct role of TLR4 activation on Th17 differentiation and find that activation of TLR4 pathway in $\mathrm{CD} 4^{+} \mathrm{T}$ cells promotes Th17 differentiation. Conversely, TLR4 deficiency results in decreased Th17 differentiation and mild EAE. Moreover, we demonstrate that TLR4-activated RelA can directly bind to transcriptional binding sites and negatively regulate the expression of miR-30a, a negative regulator of Th17 differentiation [38]. These results not only point out a role of TLR4 signal on Th17 differentiation in MS, but also point to a possible target for MS therapy.
Improper TLR4 activation in innate immune cells is correlated with many autoimmune diseases, including MS [50, 51]. Additionally, the increase of TLR4 in CD4 $4^{+}$ $\mathrm{T}$ cells in MS and EAE [24, 25] provides evidence of a possible TLR4-driven regulatory mechanism in Th17 differentiation. Different from previous research using differentiated $\mathrm{CD}^{+} \mathrm{T}$ cells for transplant [25], we transfer $\mathrm{CD}^{+}$naïve $\mathrm{T}$ cells into $\operatorname{Rag} 1^{-/-}$mice for EAE induction, and results show that TLR4 deficiency in $\mathrm{CD} 4^{+}$naïve $\mathrm{T}$ cells inhibits Th17 differentiation, resulting in defective EAE disease. These results align with previous reports that TLR4 expression by $\mathrm{CD} 4^{+} \mathrm{T}$ cells was essential for the development of EAE [25] and that LPS directly stimulated Th17 differentiation via TLR4 pathway [19]. However, Reynolds et al. showed that LPS had no effects on promoting Th17 polarization in vitro [25]. The reasons for this discrepancy are unclear, but one possible explanation is that LPS regulates Th17 differentiation in a dose-dependent manner. In addition, $\mathrm{CD}^{+}$naïve $\mathrm{T}$ cells stimulated by TLR4 activation proliferate more extensively, as well as exhibit enhanced survival [25] and increased infiltration $[52,53]$ in comparison with inactivated cells. In the TLR4 signal pathway, NF- $\mathrm{kB}$ is an ubiquitous transcription factor that plays an important role in controlling the expression of genes involved in immunity and inflammation [54-56]. LPS is able to directly stimulate Th17 differentiation in vitro via phosphorylation of NF-kB1(p50) and dephosphorylation of RelB [19]. RelA transcription factor drives Th17 differentiation by directly activating Roryt expression [57]. Moreover, knockout of myeloid differentiation factor 88 (MyD88), a key NF- $k B$ activation factor in the TLR4 signal pathway, leads to decreased number of Th17 cells, diminished CNS inflammation, and ameliorated EAE [58]. Overall, these data provide evidences for a mechanism by which TLR4 activation directly induces Th17 differentiation.

Our previous data showed the disordered miR-30a levels in vivo contributed to Th17 ratio imbalance and EAE pathology [38]. In this paper, we further explore the reason for dysregulated expression of miR-30a. Using a series of bioinformatic analyses and experimental tests (luciferase data, ChIP, EMSA, and site-mutated construct data), we demonstrate that miR-30a is a target of RelA, which binds directly to the conserved BS- 1 sequence located about $4000 \mathrm{bp}$ upstream of the miR-30a gene to silence expression. In our paper, the result of ChIP identified two potential RelA binding sites, BS-1 and BS-2, while EMSA and site-mutation experiment showed no RelA binding within BS-2. One reason for this inconsistence may be that the BS-1 and BS-2 sites are too close to each other, preventing quantification as an independent event in ChIP assay. Taken together, our results demonstrate that TLR4-triggered pathway 


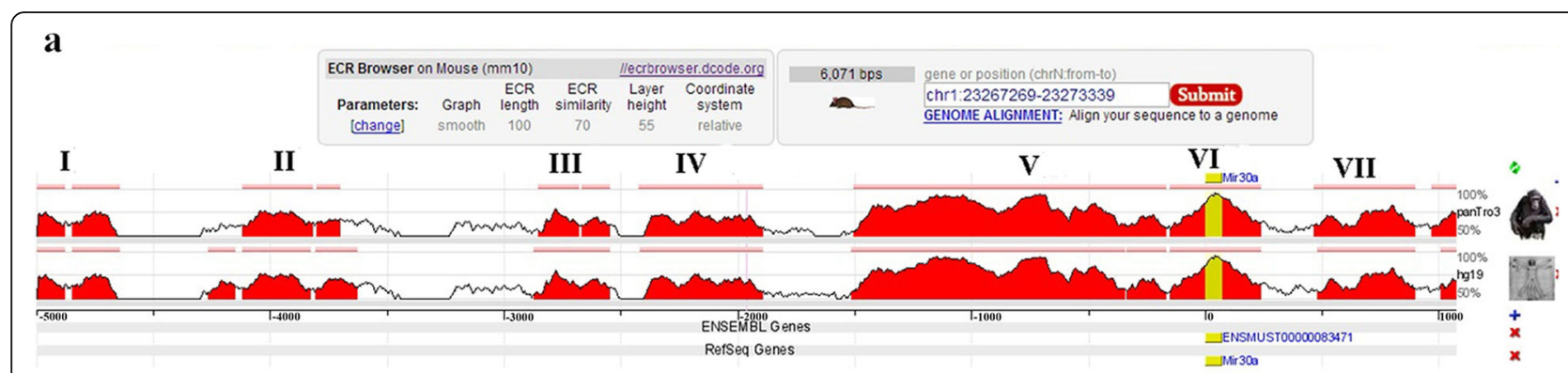

b

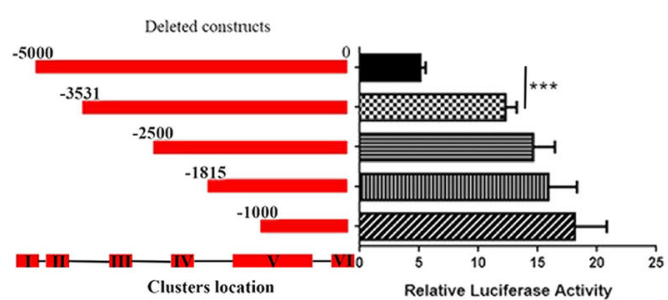

d

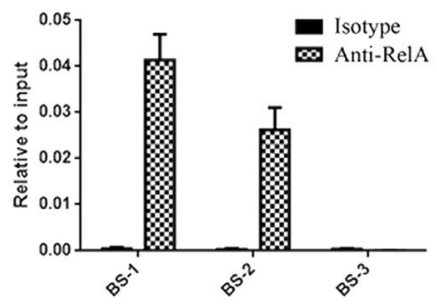

e

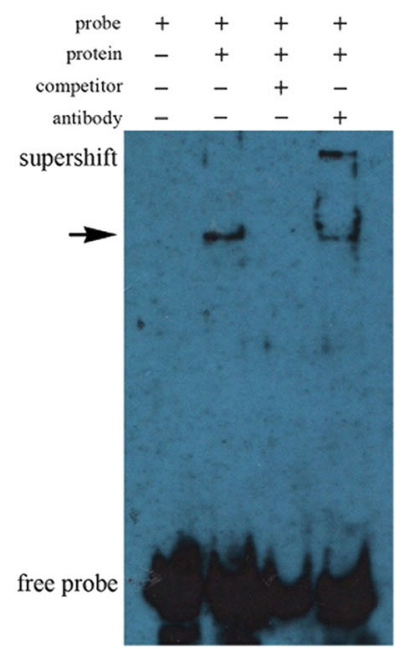

c

\begin{tabular}{|c|c|c|c|c|c|c|c|}
\hline delID & Model name & Score & Relative score & Start Es & & Strand | & predicted site sequence \\
\hline VR:00101.1 & REL & 6.776 & 0.8102911932702 & \begin{tabular}{l|l}
388 & 3 \\
\end{tabular} & 397 & 1 & GGTGITाTC \\
\hline R:0101.1 1 & REL & 6.625 & 0.805660477734136 & $9011^{5}$ & 910 & 1 & AGGGITITC \\
\hline HR:0778.1 & NFKB2 & \begin{tabular}{|c|c|c|}
9008 & \\
\end{tabular} & 0.871886222334484 & \begin{tabular}{|l|l|}
1050 & 1 \\
\end{tabular} & 1062 & -1 & GGGGACITCCCA \\
\hline 11:0778. 1 & NFKB2 & 10.344 & 0.876981784396595 & \begin{tabular}{|l|l|}
1050 & 1 \\
\end{tabular} & 1062 & 1 & TGGGAAGTCCOCO \\
\hline ML:0078.1 & NFKB2 & 3.982 & 0.802628651737993 & \begin{tabular}{|l|l|l|}
1051 & 1 & \\
\end{tabular} & 1063 & -1 & AGGGGACTICCC \\
\hline IR:0101.1 1 & REL & \begin{tabular}{|l|l|}
7311 & \\
\end{tabular} & 0.826690033083405 & \begin{tabular}{|l|l|}
1051 & 1 \\
\end{tabular} & 1060 & 1 & GGGAAGTTCC \\
\hline It:0107.1 & RELA & 8.623 & 0.8260756559665438 & 1051 & 1000 & 1 & GGGAAGTCC \\
\hline IR:0101. 1 & REL & 12007 & 0.970710219555953 & \begin{tabular}{|l|l|l|l|l|l|}
1052 & 1 \\
\end{tabular} & 1061 & -1 & GGGACTTCC \\
\hline 1R:0107.1 1 & RELA & 13.824 & 0962177252590682 & \begin{tabular}{|l|l|l|}
1052 & 1 & \\
\end{tabular} & 10611 & - 1 & GGGACTITCC \\
\hline IR:0101.1 1 & REL & \begin{tabular}{|c|c|}
0.118 & \\
\end{tabular} & 0.851446294259566 & \begin{tabular}{|l|l|l|}
1053 & 1 & \\
\end{tabular} & 1062 & -1 & GGGGACITC \\
\hline H:0101.1.1 & REL & 7.338 & 0.827526041821642 & \begin{tabular}{|l|l|}
1096 & 1 \\
\end{tabular} & 1005 & 1 & TGGAATCTCC \\
\hline IR:0107.1 & RELA & 9.531 & 0.84983668734783 & 1096 & 105 & 1 & TGGAATCTCC \\
\hline IR:0101.1 1 & REL & 10.554 & 0.926151022642705 & \begin{tabular}{|l|l|}
1097 & 1 \\
\end{tabular} & 1006 & -1 & GGGAGATTCC \\
\hline UA01007.1 & RELA & 11.663 & 0.905627529439086 & 1097 & 1106 & -1 & GGGAGATCC \\
\hline IR:0101.1 1 & REL & 6.509 & 0.80210310685875 & 1178 & 1187 & -1 & TGGGTTATC \\
\hline NR0101.1 1 & REL & 7.159 & 0.822036650557037 & \begin{tabular}{|l|l|}
1255 \\
\end{tabular} & 1264 & 1 & GGGTGATTTC \\
\hline 80101.1 & REL & 6.913 & 0.814492570941993 & \begin{tabular}{|l|l|}
1256 & \\
\end{tabular} & 1265 & & GGTGATTCA \\
\hline It:0101. 1 & REL & 9.091 & 0.881285275826407 & \begin{tabular}{|l|l|}
1712 & \\
\end{tabular} & 1721 & -1 & GGGGTाTCA \\
\hline rk0107.1 & RELA & 8.096 & 0.812285159017177 & \begin{tabular}{|l|l|}
1712 \\
\end{tabular} & 1721 & -1 & GGGGTITCA \\
\hline M:0107.1 1 & RELA & 11262 & 0.895134036156443 & 1994 & 1973 & & GGGAAGTCC \\
\hline IR:0101.1 1 & REL & 6.656 & 0.806611154433593 & 1965 & 1994 & -1 & AGGAACTICC \\
\hline No10101.1. & REL & 7.117 & 0.820746636964224 & 3510 & 3519 & 1 & TGGTAATTC \\
\hline H:0101.1 1 & REL & 6.513 & 0.80222577481997 & \begin{tabular}{|l|l|l|l|l|} 
& \\
\end{tabular} & 4117 & & GGGGATTTT \\
\hline It:0101. 1 & REL & 6.475 & 0.801060429188378 & \begin{tabular}{|l|l|}
4191 & \\
\end{tabular} & 4200 & -1 & TGTGCCTCC \\
\hline B01007.1. & RELA & 8.799 & 0.8306801482652333 & \begin{tabular}{|l|l|}
4416 & \\
\end{tabular} & 4225 & & CAGAG ITCC \\
\hline UR00101.1 & REL & 7.379 & 0.0287833388424149 & |4928 & 4937 & 1 & GGGAGITTT \\
\hline 10. & KELA & 9.974 & 0.061422249752345 & & 14937 & & GGGAGTITT \\
\hline
\end{tabular}

f

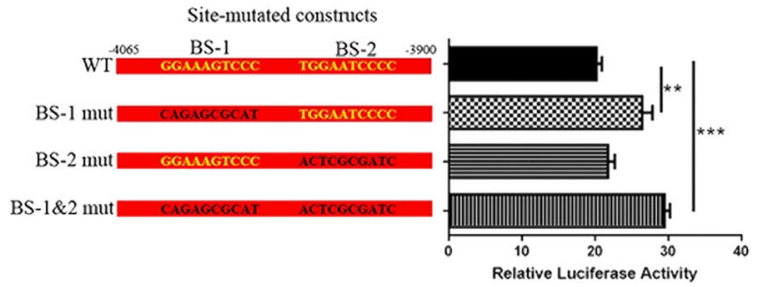

Fig. 5 RelA binds to specific sites in the regulatory elements of miR-30a gene. a An expanded view of a 6-kb region ( -5000 bp 1000 bp of miR-30a gene) centered on the homologous binding sites of transcription factors among the species of mouse, human, and chimp. The region is divided into 7 parts (I-VII) according to the binding sites. Peaks represent the level of homology. b Binding site deletion analyses in the 5-kb up-stream region of miR-30a gene using a luciferase assay. On the left side is a schematic representation of the deleted DNA sequences carrying different clusters. The right panel shows luciferase activity normalized to Renilla luciferase activity. The construct carrying all clusters is used as control. c RelA binding sites in the 6-kb region. Red box shows the concentration of binding sites in cluster II. $\mathbf{d}$ The recruitment of RelA to different binding sites (BS) located in cluster II is tested by ChIP assay. The values are normalized to the input for each sample. e EMSA shows the combination between RelA and specific sequence. Binding complexes (arrow) are identified by supershift band with antibody against RelA. $\mathbf{f}$ Effects of binding-site mutagenesis on the RelA-mediated regulation. On the left side is a schematic representation of the normal (yellow) and site-directed altered (black) constructs. The right panel shows the luciferase activity normalized to Renilla luciferase activity. The construct with no site-directed alteration (WT) is used as control. Data are presented as mean \pm standard deviation. ${ }^{* *} P<0.01$. ${ }^{* * *} P<0.001$; one-way ANOVA. Data are representative of three experiments done in triplicate 


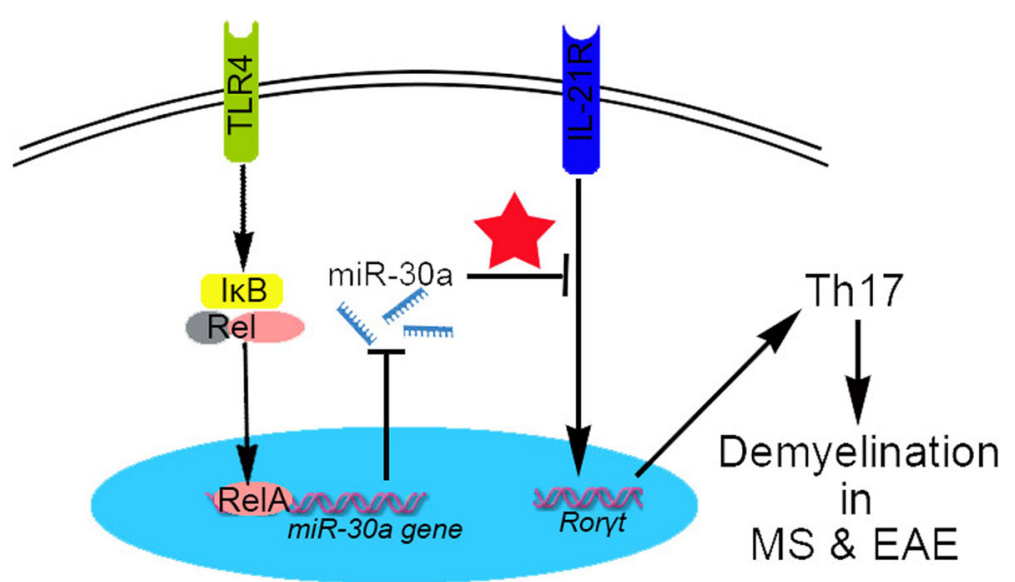

Fig. 6 Schematic model of TLR4-RelA-miR-30a signal pathway regulating Th17 differentiation. The expression of miR-30a, a negative regulator in Th17 differentiation, is inhibited by TLR4-RelA signal. This process likely contributes to the Th17 development and demyelination in MS and EAE. Red star denotes our previous results [38]

involving RelA-mediated suppression of miR-30a and its downstream target IL-21R directly regulates Th17 differentiation and EAE development (Fig. 6).

\section{Conclusions}

Currently, several available immune inhibitor therapies for MS have achieved satisfactory effects [59, 60], but it is still difficult to fundamentally protect patients from relapsing MS. Thus, searching for more effective and more feasible therapies is the top priority for MS treatment. Here, we evaluate that (1) $\mathrm{TLR} 4^{-1-} \mathrm{CD} 4^{+}$naïve T cells inhibit their differentiation into Th17; (2) transfer of $\mathrm{TLR}^{-/-} \mathrm{CD} 4^{+}$naïve $\mathrm{T}$ cells into $\mathrm{Rag} 1^{-/-}$mice is defective in promoting EAE, a model of MS; and (3) TLR4-RelA-miR-30a signal pathway regulates Th17 differentiation via direct binding of RelA to the silencing element of miR-30a, an inhibitor for Th17 differentiation we previously proved. These researches not only point out the TLR4 activation as a reason for Th17 disorder in MS, but also demonstrate that modulating TLR4-RelAmiR-30a signal in Th17 may be a possible target for MS therapy.

\section{Supplementary information}

Supplementary information accompanies this paper at https://doi.org/10. 1186/s12974-019-1579-0.

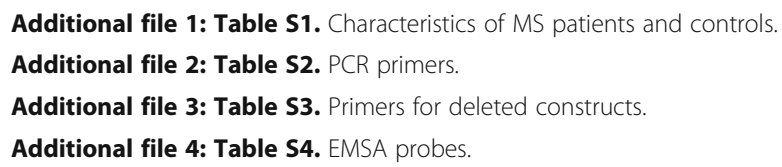

Additional file 5: Figure S1. Pattern diagram showing the sequences and locations of primers for ChIP-PCR. The sequences in yellow show the predicted RelA binding sites (BS-1, BS-2 and BS-3).
Additional file 6: Figure S2. TLR4 ${ }^{--} \mathrm{CD}^{+}$naïve $T$ cells transferred

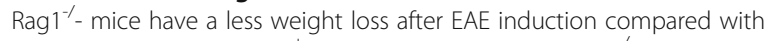
that of wild type (WT) CD4 ${ }^{+}$naïve T cells transferred Rag $1^{-1}$ - mice. The ratio of body weight is normalized to initial weight of each mouse. $N=5$ per group. Data are presented as mean \pm Standard Deviation. ${ }^{*} P<0.05$. ${ }^{* *} P<0.01$. ${ }^{* *} P<0.001$ compared with WT group; Two-way repeated measures ANOVA. Data are representative of three experiments done in triplicate.

Additional file 7: Figure S3. The predicted transcription factors binding sites in cluster II of miR-30a gene by rVista online. Red boxes show the main binding sites of NF-KB.

Additional file 8: Figure S4. Gel electropherogram of ChIP-PCR products at three predicted RelA binding sites (BS-1, BS-2 and BS-3). M, DL2000 DNA marker.

Additional file 9: Figure S5. The interaction between RelA and BS-2 probe is identified by EMSA. No specific supershift band is observed when RelA antibody added.

\section{Abbreviations}

ChIP: Chromatin immunoprecipitation; CNS: Central nervous system; EAE: Experimental autoimmune encephalomyelitis; EMSA: Electrophoretic mobility shift assay; miRNA: MicroRNA; MS: Multiple sclerosis; Th17: T helper cell 17; TLR4: Toll-like receptor 4; WT: Wild type

\section{Acknowledgements}

We thank the Affiliated Hospital of Xuzhou Medical University and Xuzhou Central Hospital for the clinical samples. We thank LetPub for its linguistic assistance during the preparation of this manuscript.

\section{Authors' contributions}

$\mathrm{XQ}$ and $\mathrm{RY}$ designed the study, performed the experiments, analyzed the data, and wrote the paper. $J H, Y Z$, and XW performed the experiments. HF, $\mathrm{FH}$, and RY reviewed the manuscript. All authors read and approved the final manuscript.

\section{Funding}

This work was supported by grants from the National Natural Science Foundation of China $(81771337,81271345)$, the National Key R\&D Program of China (2017YFA0104202), the Natural Science Foundation of Jiangsu Province (BK20161174), 333 Project of Jiangsu Province, and the Xuzhou Medical University Scientific Research Fund for Talents. 


\section{Availability of data and materials}

The datasets used and/or analyzed during the current study are available from the corresponding author on reasonable request.

\section{Ethics approval and consent to participate}

Written informed consent was obtained from all of the clinic participants. Research protocols were approved by the appropriate institutional review boards in Xuzhou Medical University Ethics Committee.

All experiments were performed in accordance with the Provisions and General Recommendations of the Chinese Experimental Animal Administration Legislation, as well as institutional approval from the Xuzhou Medical University Experimental Animal Ethics Committee.

\section{Consent for publication}

All the patients consent to publish their information details.

\section{Competing interests}

The authors declare that they have no competing interests.

\section{Author details}

${ }^{1}$ Department of Cell Biology and Neurobiology, Xuzhou Key Laboratory of Neurobiology, Xuzhou Medical University, Xuzhou 221009, Jiangsu, People's Republic of China. ${ }^{2}$ Department of Neurology, Affiliated Hospital of Xuzhou Medical University, Xuzhou 221002, Jiangsu, China. ${ }^{3}$ School of Life Science, Jiangsu Normal University, Xuzhou 221116, Jiangsu, China. ${ }^{4}$ Institute of Neurological Diseases of Xuzhou Medical University, Xuzhou 221002, Jiangsu, China.

Received: 21 June 2019 Accepted: 10 September 2019

Published online: 27 September 2019

\section{References}

1. Marta M, Meier UC, Lobell A. Regulation of autoimmune encephalomyelitis by toll-like receptors. Autoimmun Rev. 2009;8:506-9.

2. Compston A, Coles A. Multiple sclerosis. Lancet. 2008;372:1502-17.

3. Kawakami N, Bartholomaus I, Pesic M, Mues M. An autoimmunity odyssey: how autoreactive T cells infiltrate into the CNS. Immunol Rev. 2012;248:140-55.

4. Duffy SS, Lees JG, Moalem-Taylor G. The contribution of immune and glial cell types in experimental autoimmune encephalomyelitis and multiple sclerosis. Mult Scler Int. 2014;2014:285245.

5. Komiyama Y, Nakae S, Matsuki T, Nambu A, Ishigame H, Kakuta S, Sudo K, Iwakura Y. IL-17 plays an important role in the development of experimental autoimmune encephalomyelitis. J Immunol. 2006;177:566-73.

6. Codarri L, Gyulveszi G, Tosevski V, Hesske L, Fontana A, Magnenat L, Suter T, Becher B. RORgammat drives production of the cytokine GM-CSF in helper $T$ cells, which is essential for the effector phase of autoimmune neuroinflammation. Nat Immunol. 2011;12:560-7.

7. El-Behi M, Ciric B, Dai H, Yan Y, Cullimore M, Safavi F, Zhang GX, Dittel $B N$, Rostami A. The encephalitogenicity of $T(H) 17$ cells is dependent on IL-1- and IL-23-induced production of the cytokine GM-CSF. Nat Immunol. 2011;12:568-75.

8. Nacka-Aleksic M, Djikic J, Pilipovic I, Stojic-Vukanic Z, Kosec D, Bufan B, Arsenovic-Ranin N, Dimitrijevic M, Leposavic G. Male rats develop more severe experimental autoimmune encephalomyelitis than female rats: sexual dimorphism and diergism at the spinal cord level. Brain Behav Immun. 2015:49:101-18.

9. Uematsu S, Akira S. Toll-like receptors and innate immunity. J Mol Med (Berl). 2006;84:712-25.

10. Gambuzza M, Licata N, Palella E, Celi D, Foti Cuzzola V, Italiano D, Marino S, Bramanti P. Targeting Toll-like receptors: emerging therapeutics for multiple sclerosis management. J Neuroimmunol. 2011;239:1-12.

11. Fallarino F, Gargaro M, Mondanell G, Downer EJ, Hossain MJ, Gran B. Delineating the role of Toll-like receptors in the neuro-inflammation model EAE. Methods Mol Biol. 2016;1390:383-411.

12. Jonas A, Thiem S, Kuhlmann T, Wagener R, Aszodi A, Nowell C, Hagemeier $K$, Laverick L, Perreau V, Jokubaitis V, et al. Axonally derived matrilin-2 induces proinflammatory responses that exacerbate autoimmune neuroinflammation. J Clin Invest. 2014;124:5042-56.
13. Zhou Y, Ye L, Wan Q, Zhou L, Wang X, Li J, Hu S, Zhou D, Ho W. Activation of Toll-like receptors inhibits herpes simplex virus-1 infection of human neuronal cells. J Neurosci Res. 2009;87:2916-25.

14. Guo X, Harada C, Namekata K, Matsuzawa A, Camps M, Ji H, Swinnen D, Jorand-Lebrun C, Muzerelle M, Vitte PA, et al. Regulation of the severity of neuroinflammation and demyelination by TLR-ASK1-p38 pathway. EMBO Mol Med. 2010;2:504-15.

15. Wolf NA, Amouzegar TK, Swanborg RH. Synergistic interaction between Tolllike receptor agonists is required for induction of experimental autoimmune encephalomyelitis in Lewis rats. J Neuroimmunol. 2007;185:115-22.

16. Waldner H, Collins M, Kuchroo VK. Activation of antigen-presenting cells by microbial products breaks self tolerance and induces autoimmune disease. Clin Invest. 2004;113:990-7.

17. Mellanby RJ, Cambrook H, Turner DG, O'Connor RA, Leech MD, Kurschus FC, MacDonald AS, Arnold B, Anderton SM. TLR-4 ligation of dendritic cells is sufficient to drive pathogenic $T$ cell function in experimental autoimmune encephalomyelitis. J Neuroinflammation. 2012;9:248.

18. Kerfoot SM, Long EM, Hickey MJ, Andonegui G, Lapointe BM, Zanardo RC, Bonder C, James WG, Robbins SM, Kubes P. TLR4 contributes to diseaseinducing mechanisms resulting in central nervous system autoimmune disease. J Immunol. 2004;173:7070-7.

19. Park JH, Jeong SY, Choi AJ, Kim SJ. Lipopolysaccharide directly stimulates Th17 differentiation in vitro modulating phosphorylation of RelB and NFkappaB1. Immunol Lett. 2015;165:10-9.

20. Benveniste EN. Role of macrophages/microglia in multiple sclerosis and experimental allergic encephalomyelitis. J Mol Med (Berl). 1997;75:165-73.

21. Miron VE, Boyd A, Zhao JW, Yuen TJ, Ruckh JM, Shadrach JL, van Wijngaarden P, Wagers AJ, Williams A, Franklin RJM, Ffrench-Constant C. M2 microglia and macrophages drive oligodendrocyte differentiation during CNS remyelination. Nat Neurosci. 2013;16:1211-8.

22. Roses RE, Xu S, Xu M, Koldovsky U, Koski G, Czerniecki BJ. Differential production of IL-23 and IL-12 by myeloid-derived dendritic cells in response to TLR agonists. J Immunol. 2008;181:5120-7.

23. Kebir H, Ifergan I, Alvarez JI, Bernard M, Poirier J, Arbour N, Duquette P, Prat A. Preferential recruitment of interferon-gamma-expressing TH17 cells in multiple sclerosis. Ann Neurol. 2009;66:390-402.

24. Brummelman J, Raeven RH, Helm K, Pennings JL, Metz B, van Eden W, van Els CA, Han WG. Transcriptome signature for dampened Th2 dominance in acellular pertussis vaccine-induced CD4(+) T cell responses through TLR4 ligation. Sci Rep. 2016;6:25064.

25. Reynolds JM, Martinez GJ, Chung Y, Dong C. Toll-like receptor 4 signaling in T cells promotes autoimmune inflammation. Proc Natl Acad Sci U S A. 2012; 109:13064-9.

26. Li J, Wan Y, Guo Q, Zou L, Zhang J, Fang Y, Zhang J, Zhang J, Fu X, Liu H, et al. Altered microRNA expression profile with miR-146a upregulation in CD4+ T cells from patients with rheumatoid arthritis. Arthritis Res Ther. 2010;12:R81.

27. Zhernakova A, Withoff S, Wijmenga C. Clinical implications of shared genetics and pathogenesis in autoimmune diseases. Nat Rev Endocrinol. 2013;9:646-59.

28. Krol J, Loedige I, Filipowicz W. The widespread regulation of microRNA biogenesis, function and decay. Nat Rev Genet. 2010;11:597-610.

29. Augoff K, McCue B, Plow EF, Sossey-Alaoui K. miR-31 and its host gene InCRNA LOC554202 are regulated by promoter hypermethylation in triplenegative breast cancer. Mol Cancer. 2012;11:5.

30. Toyota M, Suzuki H, Sasaki Y, Maruyama R, Imai K, Shinomura Y, Tokino T. Epigenetic silencing of microRNA-34b/c and B-cell translocation gene 4 is associated with $\mathrm{CpG}$ island methylation in colorectal cancer. Cancer Res. 2008:68:4123-32.

31. Botla SK, Savant S, Jandaghi P, Bauer AS, Mucke O, Moskalev EA, Neoptolemos JP, Costello E, Greenhalf W, Scarpa A, et al. Early epigenetic downregulation of microRNA-192 expression promotes pancreatic cancer progression. Cancer Res. 2016;76:4149-59.

32. Yang N, Coukos G, Zhang L. MicroRNA epigenetic alterations in human cancer: one step forward in diagnosis and treatment. Int J Cancer. 2008;122:963-8.

33. Scott GK, Mattie MD, Berger CE, Benz SC, Benz CC. Rapid alteration of microRNA levels by histone deacetylase inhibition. Cancer Res. 2006;66: 1277-81.

34. Piriyapongsa J, Jordan IK, Conley AB, Ronan T, Smalheiser NR. Transcription factor binding sites are highly enriched within microRNA precursor sequences. Biol Direct. 2011;6:61. 
35. Wang Z, Yao H, Lin S, Zhu X, Shen Z, Lu G, Poon WS, Xie D, Lin MC, Kung HF. Transcriptional and epigenetic regulation of human microRNAs. Cancer Lett. 2013;331:1-10.

36. Li T, Guo H, Zhao X, Jin J, Zhang L, Li H, Lu Y, Nie Y, Wu K, Shi Y, Fan D. Gastric cancer cell proliferation and survival is enabled by a cyclophilin B/ STAT3/miR-520d-5p signaling feedback loop. Cancer Res. 2017:77:1227-40.

37. Georges SA, Biery MC, Kim SY, Schelter JM, Guo J, Chang AN, Jackson AL, Carleton MO, Linsley PS, Cleary MA, Chau BN. Coordinated regulation of cell cycle transcripts by p53-Inducible microRNAs, miR-192 and miR-215. Cancer Res. 2008;68:10105-12.

38. Qu X, Zhou J, Wang T, Han J, Ma L, Yu H, Geng D, Fan H, Zhang Q, Hua F, Yao R. MiR-30a inhibits Th17 differentiation and demyelination of EAE mice by targeting the IL-21R. Brain Behav Immun. 2016;57:193-9.

39. Kurtzke JF. Rating neurologic impairment in multiple sclerosis: an expanded disability status scale (EDSS). Neurology. 1983;33:1444-52.

40. Kozomara A, Birgaoanu M, Griffiths-Jones S. miRBase: from microRNA sequences to function. Nucleic Acids Res. 2019:47:D155-62

41. Haeussler M, Zweig AS, Tyner C, Speir ML, Rosenbloom KR, Raney BJ, Lee CM, Lee BT, Hinrichs AS, Gonzalez JN, et al. The UCSC Genome Browser database: 2019 update. Nucleic Acids Res. 2019;47:D853-8.

42. Ovcharenko I, Nobrega MA, Loots GG, Stubbs L. ECR Browser: a tool for visualizing and accessing data from comparisons of multiple vertebrate genomes. Nucleic Acids Res. 2004;32:W280-6.

43. Khan A, Fornes O, Stigliani A, Gheorghe M, Castro-Mondragon JA, van der Lee R, Bessy A, Cheneby J, Kulkarni SR, Tan G, et al. JASPAR 2018: update of the open-access database of transcription factor binding profiles and its web framework. Nucleic Acids Res. 2018:46:D1284.

44. Loots GG, Ovcharenko I. rVISTA 2.0: evolutionary analysis of transcription factor binding sites. Nucleic Acids Res. 2004;32:W217-21.

45. Birrell MA, Hardaker E, Wong S, McCluskie K, Catley M, De Alba J, Newton R, Haj-Yahia S, Pun KT, Watts CJ, et al. Ikappa-B kinase-2 inhibitor blocks inflammation in human airway smooth muscle and a rat model of asthma. Am J Respir Crit Care Med. 2005;172:962-71.

46. Lyss G, Knorre A, Schmidt TJ, Pahl HL, Merfort I. The anti-inflammatory sesquiterpene lactone helenalin inhibits the transcription factor NF-kappaB by directly targeting p65. J Biol Chem. 1998;273:33508-16.

47. Haase S, Wilck N, Kleinewietfeld M, Muller DN, Linker RA. Sodium chloride triggers Th17 mediated autoimmunity. J Neuroimmunol. 2019;329:9-13.

48. Wu X, Tian J, Wang S. Insight into non-pathogenic Th17 cells in autoimmune diseases. Front Immunol. 2018;9:1112.

49. Liu C, Yang H, Shi W, Wang T, Ruan Q. MicroRNA-mediated regulation of Th17/Treg balance in autoimmune disease. Immunology. 2018;155:427-34.

50. Duperray A, Barbe D, Raguenez G, Weksler BB, Romero IA, Couraud PO, Perron $\mathrm{H}$, Marche PN. Inflammatory response of endothelial cells to a human endogenous retrovirus associated with multiple sclerosis is mediated by TLR4. Int Immunol. 2015;27:545-53.

51. Crowley T, Fitzpatrick JM, Kuijper T, Cryan JF, O'Toole O, O'Leary OF, Downer EJ. Modulation of TLR3/TLR4 inflammatory signaling by the GABAB receptor agonist baclofen in glia and immune cells: relevance to therapeutic effects in multiple sclerosis. Front Cell Neurosci. 2015;9:284.

52. Egan CE, Sodhi CP, Good M, Lin J, Jia H, Yamaguchi Y, Lu P, Ma C, Branca MF, Weyandt $S$, et al. Toll-like receptor 4-mediated lymphocyte influx induces neonatal necrotizing enterocolitis. J Clin Invest. 2016;126:495-508.

53. Jia H, Sodhi CP, Yamaguchi Y, Lu P, Ladd MR, Werts A, Fulton WB, Wang S, Prindle T Jr, Hackam DJ. Toll like receptor 4 mediated lymphocyte imbalance induces Nec-induced lung injury. Shock. 2018;52:215-23.

54. Roozbehkia M, Mahmoudi M, Aletaha S, Rezaei N, Fattahi MJ, JafarnezhadAnsariha F, Barati A, Mirshafiey A. The potent suppressive effect of beta-dmannuronic acid (M2000) on molecular expression of the TLR/NF-kB Signaling Pathway in ankylosing spondylitis patients. Int Immunopharmacol. 2017:52:191-6.

55. Qian L, Chen W, Wang S, Liu Y, Jia X, Fu Y, Gong W, Tian F. FcyRllb attenuates TLR4-mediated NF-KB signaling in B cells. Mol Med Rep. 2017;16: 5693-8.

56. Ahmad SF, Ansari MA, Nadeem A, Bakheet SA, Al-Ayadhi LY, Attia SM. Tolllike receptors, NF-KB, and IL-27 mediate adenosine A2A receptor signaling in BTBR T(+) Itpr3(tf)/J mice. Prog Neuro-Psychopharmacol Biol Psychiatry. 2017;79:184-91.

57. Ruan Q, Kameswaran V, Zhang Y, Zheng S, Sun J, Wang J, DeVirgiliis J, Liou $\mathrm{HC}$, Beg AA, Chen YH. The Th17 immune response is controlled by the RelRORy-RORy T transcriptional axis. J Exp Med. 2011;208:2321-33.
58. Marta M, Andersson A, Isaksson M, Kampe O, Lobell A. Unexpected regulatory roles of TLR4 and TLR9 in experimental autoimmune encephalomyelitis. Eur J Immunol. 2008;38:565-75.

59. Saidha S, Eckstein C, Calabresi PA. New and emerging disease modifying therapies for multiple sclerosis. Ann N Y Acad Sci. 2012;1247:117-37.

60. Zhao YF, Zhang X, Ding ZB, Yang XW, Zhang H, Yu JZ, Li YH, Liu CY, Zhang $\mathrm{Q}$, Zhang $\mathrm{HZ}$, et al. The therapeutic potential of Rho kinase inhibitor fasudil derivative FaD-1 in experimental autoimmune encephalomyelitis. J Mol Neurosci. 2015:55:725-32.

\section{Publisher's Note}

Springer Nature remains neutral with regard to jurisdictional claims in published maps and institutional affiliations.
Ready to submit your research? Choose BMC and benefit from:

- fast, convenient online submission

- thorough peer review by experienced researchers in your field

- rapid publication on acceptance

- support for research data, including large and complex data types

- gold Open Access which fosters wider collaboration and increased citations

- maximum visibility for your research: over $100 \mathrm{M}$ website views per year

At BMC, research is always in progress.

Learn more biomedcentral.com/submissions 